\title{
MS17-P06 | PhASE TRANSFORMATIONS OF (RS)-2-ChLOROMANDELIC ACID IN THE SOLID STATE: FROM RACEMIC COMPOUND TO CONGLOMERATE UNDER MECHANICAL FORCE
}

LIU, JIE (Laboratoire de Chimie des Polymeres, Brussels, BEL); Liu, Guangfeng (Laboratoire de Chimie des Polymeres, Brussels, BEL); Geerts, Yves (Laboratoire de Chimie des Polymeres, Brussels, BEL)

(RS)-2-Chloromandelic acid being chiral compound can exist as a racemic compound or a conglomerate. And the phase transition occurs between the polymorphic racemic compounds and conglomerate. It is of importance to study the phase transformations especially in the solid state, which is beneficial for the pharmaceutical factories to control the polymorphs very well. The transition from metastable racemic compounds to conglomerate under the application of grinding was disclosed. The metastable racemic compounds, form $\beta$, were prepared by recrystallization from the melt of commercially available racemic compounds Form $\alpha$. The form $\beta$ can be stable for days in air without additional forces. However, the crystals of form $\beta$ transforms to crystalline conglomerate quickly when the mechanical force (e.g. grind) was applied. 